\title{
Giant Cell Tumor of Distal Radius: En Bloc Resection and Partial Wrist Arthrodesis Using Non-Vascularized Fibular Autograft
}

\author{
Davod Jafari, ${ }^{1}$ Hooman Shariatzadeh, ${ }^{1}$ Mohammad Ali Okhovatpour,, ${ }^{1,}$ Mehran Razavipour, ${ }^{1}$ and \\ Farshad Safdari ${ }^{2}$ \\ ${ }^{1}$ Bone and Joint Reconstruction Research Center, Shafa Orthopedic Hospital, Iran University of Medical Sciences, Tehran, IR Iran \\ ${ }^{2}$ Medical Research Assistant, Orthotist and Prosthetist, Bone Joint and Related Tissues Research Center, Akhtar hospital, Shahid Beheshti University of Medical Sciences, \\ Tehran, IR Iran \\ "Corresponding author: Mohammad Ali Okhovatpour, Bone and Joint Reconstruction Research Center, Shafa Orthopedic Hospital, Baharestan Sq, Tehran, Iran. Tel: \\ +98-2133542041, Fax: +98-2133542042, E-mail: okhovatortho@gmail.com \\ Received 2017 April 15; Accepted 2017 April 20.
}

\begin{abstract}
Background: Despite several surgical techniques introduced for the treatment of distal radial giant cell tumor (GCT), most appropriate treatments remain to be discovered.

Objectives: The current study reported on the results of en bloc resection and partial wrist arthrodesis using non-vascularized fibular shaft.

Methods: Between 2004 and 2014, 7 patients with distal radial GCT (Campanacci grade III) were treated by en bloc resection and partial wrist arthrodesis using non-vascularized fibular shaft. Arthrodesis was performed using an intramedullary pin. Patients were followed for $59 \pm 38$ months. At the last visit, active range of wrist motions, modified musculoskeletal tumor society (MSTS) scoring system, instability and grip strength compared to contralateral side were measured. Also, time of union, need for further operations and recurrence of the tumor were evaluated.

Results: After $8.3 \pm 0.5$ months, complete union was achieved. The ranges of wrist flexion, wrist extension, ulnar deviation, radial deviation, supination, and pronation averaged $16.7 \pm 2.6,7.5 \pm 6.1,7.5 \pm 6.1,6.7 \pm 5.2,33.3 \pm 6.8$, and $30.8 \pm 8.6$ degrees, respectively. The mean modified MSTS score was $75.8 \pm 8 \%$. Grip strength was $53.3 \pm 6.8 \%$ of the contralateral side. Graft-related complications did not occur. Recurrence occurred in 2 patients, including one bony recurrence at the graft-wrist junction and one soft tissue recurrence (28.6\%).

Conclusions: Replacement of excised distal radius with non-vascularized fibular shaft autograft following en bloc resection and partial arthrodesis, using an intramedullary pin, could serve as an appropriate treatment of distal radial GCT.
\end{abstract}

Keywords: Radius Bone, Giant Cell Tumor, En Bloc Resection, Arthrodesis, Fibular Graft

\section{Background}

Giant cell tumor (GCT) of bone, the most common benign locally aggressive bone tumor, accounts for about $4 \%$ to $5 \%$ of all primary bone neoplasms and $20 \%$ of benign bone tumors. Distal radius is the third common site of involvement and is involved in about $10 \%$ of GCT patients ( 1 , 2).

With regards to the important role of this area in wrist function and stability and complicated anatomic and biomechanical properties of the radiocarpal and distal radioulnar joints, treatment of distal radial GCT is always challenging for surgeons. There are no absolute clinical, radiographic or histologic features that precisely predict tumor behavior (3). The distal radius has a further distinction of having more aggressive GCT with higher rate of local recurrence and metastasis $(4,5)$. Moreover, many patients receive medical attention only after attaining con- siderable size and virtually destroying the bony support of the adjacent articular surface, so a more aggressive treatment seems rational for GCT of the distal radius.

The most appropriate treatment option for distal radial GCT is unclear. The treatment is basically via extended curettage and filling the defect with bone graft or cement for most lesions. Due to the high rate of recurrence after curettage of the more progressed lesions $(4,6-8)$, most surgeons prefer to perform en bloc resection followed by reconstruction or arthrodesis. Although en bloc resection increases the chance of successful treatment of GCT, however, performing arthroplasty or arthrodesis and also selecting the most suitable graft type is controversial. Using osteochondral distal radial allograft, vascularized fibular autograft, non-vascularized fibular autograft and ulnar transposition has been suggested, each with its advantages and disadvantages (6, 8-18). 


\section{Objectives}

The current study presented mid and short term results of a technique using the non-vascularized fibular shaft (without the fibular head) as an intercalary bone graft for fibulo-scapho-lunate arthrodesis after resection of distal radius. It is believed that the technique provides both stability and some wrist mobility.

\section{Methods}

Seven patients with GCT of the distal part of the radius were treated between 2004 and 2014 at the institution of the current study. All of the patients were operated on by a senior surgeon. The patients were classified using Campanacci's grading method consisting of 3 grades (19). Grade I tumors had a well-defined border and the cortex was intact or slightly thinned but not deformed. In grade II, the tumor expands the bone yet with a relatively welldefined border and a radio-opaque cortical rim. In grade III, the lesions had fuzzy borders with cortical destruction in some areas and extension into soft tissue. According to this system, all of the patients were grade II or III.

All seven patients were evaluated preoperatively with appropriate studies consisting of plain radiographs, bone scan, and magnetic resonance imaging (MRI). Five patients had received no previous treatment and the diagnosis was confirmed by open incisional biopsy. Two patients were referred with local recurrence after curettage and bone grafting and the diagnosis of giant cell tumor was confirmed by receiving previous pathological reports. Before the study, the institutional review board approved the study. All of the patients signed an informed consent.

\subsection{Surgical Technique}

All of the patients were operated under general anesthesia in the supine position. A pneumatic tourniquet was used at both surgical sites (upper and lower extremities). After prep and drape, 2 operating teams initiated the procedure for tumor resection and fibular graft harvesting. Dorsal approach for distal radius was chosen for all patients. Biopsy tract was removed if present. Bone resection was done at the level determined preoperatively by MRI plus a safe margin of about 2 centimeters. Soft tissue component was dissected and excised completely, taking care not to damage neurovascular structures. An average of 5.6 $\pm 0.9 \mathrm{~cm}$ ( 4 to $7 \mathrm{~cm})$ of bone was resected. At the distal site, the proximal cartilage of scaphoid and lunate was resected and a slot created between them for fibular graft insertion. The second team harvested the graft from the middle-third of the contra-lateral fibula, simultaneously. The graft is resized to match the radius defect in the best wrist alignment. Wrist-graft and graft-radius fixation was achieved by a rush pin inserted through the third metacarpal in the fibulargraft and then the radius medullary canal. For more rotational stability, a second pin was introduced to cross the graft-host junction. Chips bone graft was routinely applied at fibula-radius and fibula-scapholunate junction. After careful hemostasis, the wound was closed over a suction drain and an above elbow slab was applied.

As tolerated, weight bearing was allowed early after surgery. After 2 weeks, a long arm cast was applied after suture removal for the next 6 weeks. After that, a rigid wrist brace was used until union was achieved and intramedullary rush pin was removed at that time. Patients were followed weekly in the first month, fortnightly in the next 2 months, and then on a monthly basis. After the first year, follow up was performed at 3 monthly intervals for one year and 6 monthly thereafter. X-rays were taken at every visit after the first month and evaluated for union, recurrence of tumor or graft related complications. The union time of proximal and distal ends of the graft was determined and the later was considered as the time of complete union. At the final visit, clinical outcome included grip strength and range of motion was measured using a dynamometer (Hydraulic grip gauge, SH5005, SAEHAN corporation, Korea) and goniometer, respectively. Pain, functional activity, emotional acceptance, hand positioning, dexterity and lifting ability were assessed according to the modified Musculoskeletal Tumor Society (MSTS) scoring system (20).

\section{Results}

Despite of the treatment plan, one of the patients (a 21year-old male) did not return for pin removal at the determined time. However, he returned after 18 months with a bony recurrence of the tumor at the graft-wrist junction. The functional outcomes of the patient in the study was not included, however, this patient was considered as one of the recurrence cases. It was decided to perform en-bloc resection and wrist arthrodesis using iliac crest graft for the second time (Figure 1).

The characteristics of the other patients are presented in Table 1. The patients were aged $21.3 \pm 4.5$ years at the time of resection (Range: 17 to 30). Patients were followed for $59 \pm 38$ months (range: 10 to 120). At last follow up, the ranges of wrist flexion, wrist extension, ulnar deviation, radial deviation, supination, and pronation averaged $16.7 \pm$ $2.6,7.5 \pm 6.1,7.5 \pm 6.1,6.7 \pm 5.2,33.3 \pm 6.8$, and $30.8 \pm 8.6$ degrees, respectively. The mean functional score based on the modified MSTS score was $75.8 \pm 8 \%$. Complete union was 

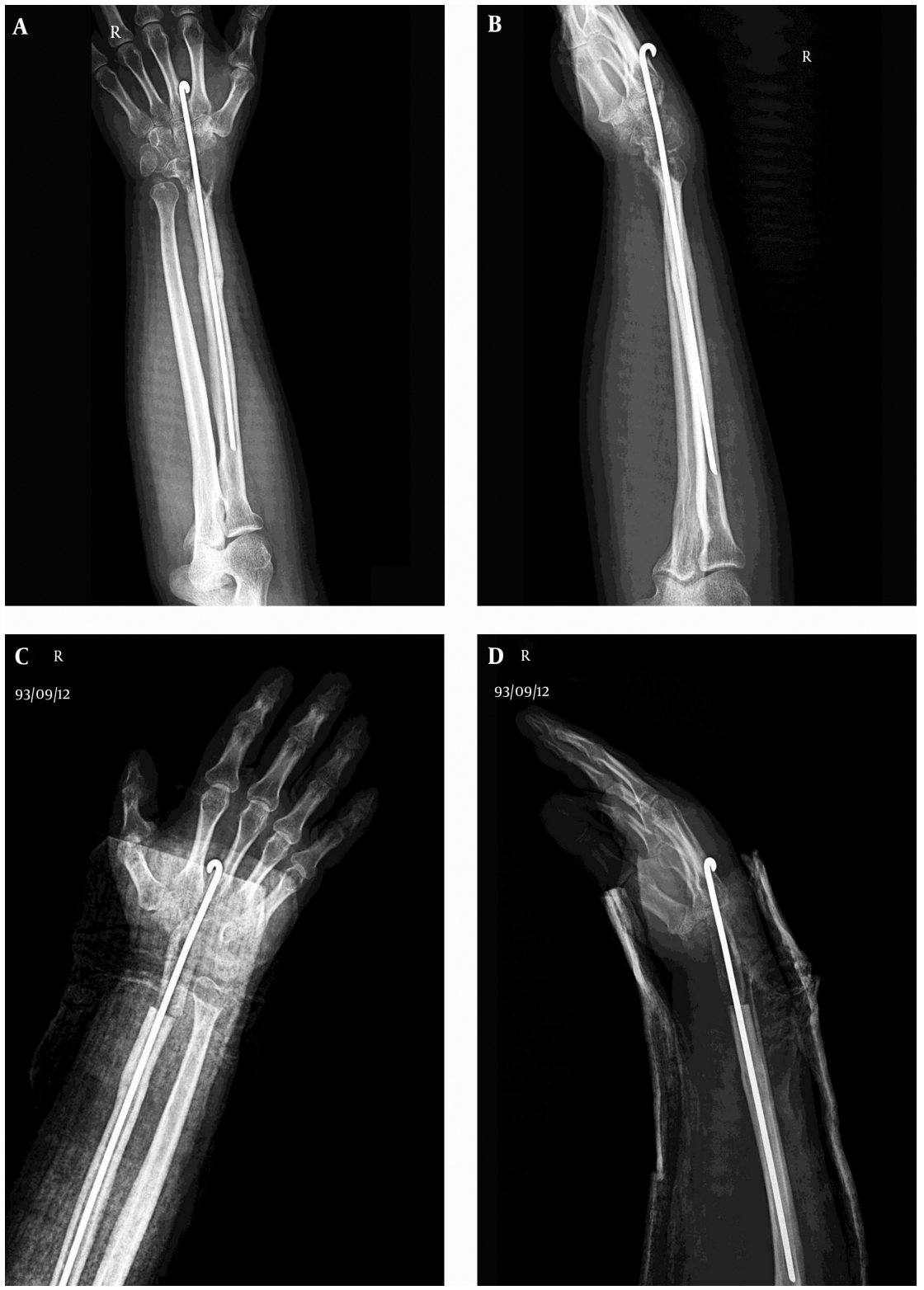

Figure 1. A and B, the $x$-rays show the recurrence of the lesion in distal radius. C and D, en-bloc resection and wrist arthrodesis using iliac crest graft was performed.

achieved after $8.3 \pm 0.5$ months (Figure 2). Grip strength was $53.3 \pm 6.8 \%$ of the contralateral side. Emotional acceptance was excellent in all patients and they were all satisfied with the esthetic results.

There was no major complication related to the procedure. Also, graft-related complications, such as resorption or fracture did not develop in the patients. There was one case of soft tissue recurrence of tumor after 9 months, which was treated with mass excision and no sign of recurrence was detected after 3 years of follow up. In total, the incidence of recurrence in the current study was $28.6 \%$.

\section{Discussion}

The study demonstrated that replacement of excised distal radius with non-vascularized fibular shaft autograft following en bloc resection and partial arthrodesis using an intramedullary pin could serve as an appropriate treatment of distal radial GCT. 
Table 1. Characteristics of the Patients with Distal Radius Giant Cell Tumor

\begin{tabular}{|c|c|c|c|c|c|c|c|c|c|c|c|c|c|c|c|c|}
\hline \multirow{2}{*}{$\begin{array}{l}\text { No. } \\
\text { Patient }\end{array}$} & \multirow{2}{*}{$\begin{array}{c}\text { Age at } \\
\text { the Time } \\
\text { of } \\
\text { Surgery } \\
\text { (y) }\end{array}$} & \multirow[t]{2}{*}{ Sex } & \multirow{2}{*}{ 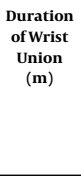 } & \multirow{2}{*}{$\begin{array}{c}\text { Duration } \\
\text { of Radio- } \\
\text { Fibular } \\
\text { Union } \\
(\mathbf{m})\end{array}$} & \multicolumn{6}{|c|}{ Range of Motion } & \multirow{2}{*}{$\begin{array}{l}\text { Length } \\
\text { of the } \\
\text { Graft }\end{array}$} & \multirow[t]{2}{*}{ MSTS } & \multirow[t]{2}{*}{ Recurrence } & \multirow{2}{*}{$\begin{array}{l}\text { Follow } \\
\text {.up }(m)\end{array}$} & \multirow{2}{*}{$\begin{array}{c}\text { Grip } \\
\text { Strength }\end{array}$} & \multirow[t]{2}{*}{ Instability } \\
\hline & & & & & Flex & Ext & $\begin{array}{c}\text { Radial } \\
\text { Dev }\end{array}$ & $\begin{array}{c}\text { Ulnar } \\
\text { Dev. }\end{array}$ & Sup & Pron & & & & & & \\
\hline 1 & 17 & $\mathrm{~F}$ & 9 & 9 & 15 & 10 & 10 & 10 & 30 & 30 & 5.5 & $85 \%$ & No & 48 & $45 \%$ & no \\
\hline 2 & 19 & м & 8 & 8 & 20 & 0 & 10 & 10 & 35 & 25 & 7 & $62 \%$ & No & 36 & $55 \%$ & no \\
\hline 3 & 20 & M & 6 & 8 & 15 & 15 & 10 & 10 & 30 & 35 & 4.5 & $72 \%$ & No & 10 & $50 \%$ & no \\
\hline 4 & 20 & $\mathrm{~F}$ & 9 & 9 & 20 & 10 & 10 & 15 & 45 & 45 & 6 & $81 \%$ & $\begin{array}{c}\text { Soft } \\
\text { tissue }\end{array}$ & 80 & $55 \%$ & no \\
\hline 5 & 22 & M & 8 & 8 & 15 & 0 & 0 & 0 & 25 & 20 & 5 & $78 \%$ & No & 120 & $65 \%$ & no \\
\hline 6 & 30 & F & 7 & 8 & 15 & 10 & 0 & 0 & 35 & 30 & 7 & $77 \%$ & No & 60 & $50 \%$ & no \\
\hline
\end{tabular}

Abbreviations: Dev, deviation; $Y$, year; Flex, flexion; Ext, extension; M, months; MSTS, musculoskeletal tumor society; Pro, pronation; Sup, supination.
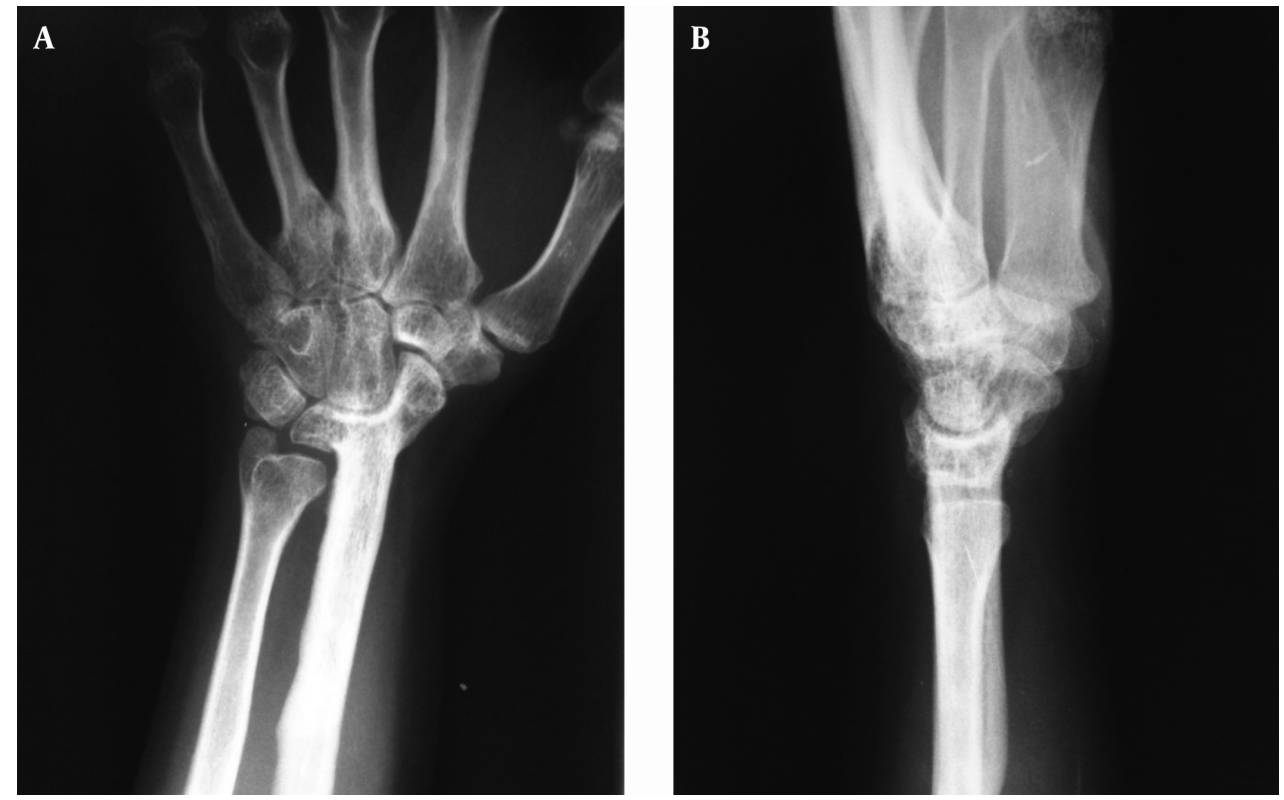

Figure 2. A and B, The final x-rays of a patient after 2 years showing no recurrence and complete union of the graft to the radial bone.

Giant cell tumor is an aggressive lesion with a high rate of recurrence. In large series, the rate of local recurrence even after modern operating techniques, supplemented by adjuvants such as phenol, high speed burr, and cementing, was $50 \%$ after only 2 years of follow up $(5,21,22)$. There are reports that GCTs in the distal radius are more aggressive and metastasize more often to the lungs (4).

Treatment and rehabilitation of the patients with a distal radial GCT is a challenging problem for orthopedic surgeons. The importance of the radial bone in normal function of the wrist joint and significant effects of wrist malfunction on activities of daily living concern the surgeons about the treatment of these patients, especially when a young patient admits with a distal radial GCT.
Although it seems that curettage of the lesion and filling the bone defect can preserve the normal joint function due to preservation of the distal radius, however, studies have shown that this treatment is associated with $27 \%$ to $54 \%$ of local lesion recurrence (18). In a meta-analysis, Liu et al. demonstrated that compared to the resection, intralesional excision is associated with higher local recurrence rate especially in grade 3 GCTs. They demonstrated that intra-lesional curettage is more appropriate for grade 1 and 2 lesions (6).

En-bloc resection of the tumor is strongly recommended for advanced stage of the distal radial GCT (Campanacci grade III), post-curettage recurrence, and tumors, which break the radial cortex (pathological fracture), en- 
large rapidly, extensively involve the bone and soft tissue with collapse of the distal radial articular surface and those that are frankly malignant to minimize the chance of recurrence $(3,8,22,23)$. However, en bloc resection has its own limitations. With this technique, the articular surface is sacrificed and it has been reported that secondary osteoarthritis is found in $13 \%$ to $50 \%$ of the patients (6). Reconstruction after en bloc resection is necessary and many techniques have been advocated including iliac crest graft, transposition of the ulna, distal radial allograft, vascularized or non-vascularized fibular graft and prosthesis $(6,8$ 18).

Ulnar transposition or reconstruction with corticocancellous graft immolates the wrist and forearm motion. Approximately, half of these patients experience stress fracture (24).

Some authors used distal radial allograft for reconstruction $(6,8)$. Although using allograft had resulted in promising outcomes, however, problems with reconstruction of the radiocarpal ligaments and late wrist instability or allograft fractures limit the use of this technique in clinical practice (9). Furthermore, finding an appropriate donor and obtaining and saving the graft, potential infection or graft rejection and delayed healing are some of the problems of this technique (9). Duan et al. found acceptable results after 5.2 years in 15 patients treated with radial allograft. They did not find non-union or allograft fracture. The GCT recurred in one patient and degenerative changes were found in all of the patients (14). However, other studies reported concerning outcomes with the use of distal radial allograft. In treatment of 15 patients with distal radial GCT (Campanacci III), Jamshidi et al. found 3 cases of recurrence (25). One patient developed nonunion and 9 patients had instability of the distal radioulnar joint. Degenerative changes were found in all of the patients. After 5.4 years, 5 patients required revision surgery due to the fracture of the allograft ( 4 patients) and recurrence of the lesion (1 patient) (25). Kocher et al. reported a high rate of arthrodesis, instability and pain and other complications following reconstruction with distal radial allograft. One patient even underwent amputation (26).

Vascularized fibular autograft is a technically demanding procedure and several complications may occur (9). This technique is expensive and associated with significant operative time and potential complications. Although vascularized fibular graft may speed up the healing of the bone, however, this operation may last often 12 to 14 hours and requires sacrificing of 2 major vessels $(9,18)$. Also, skin closure of the forearm could lead to certain problems (27). If vascularized fibular graft is used with fibular head as a wrist arthroplasty, neither the stability nor the mobility of the wrist will be comparable to a normal joint (28). Ad- ditionally, donor site problems in particular laxity of the knee may impress the results (29). These problems are the cause of limited reports about the outcomes of this technique. Recently, Chung et al. treated 12 patients with GCT stage 2 based on the Enneking classification. Union had occurred after nearly 16 weeks in all patients with moderately satisfactory grip strength, range of motion and functional outcomes. However, skin grafting was required in 5 patients. Also, subluxation and subsequent osteoarthritic changes occurred in 5 patients (11). Conversion to arthrodesis after reconstruction with vascularized fibular autograft due to the persistent pain was reported (29).

In 1945, for the first time, non-vascularized fibular autograft was used for congenital absence of the radius (30). Later, this technique was used for treatment of distal radial GCT and resulted in promising outcomes. Advantages of non-vascularized fibular grafting include rapid incorporation, easy accessibility, low risk of significant donor site morbidity, and absence of immunogenic reactions (18). However, this procedure could be associated with complications such as delayed union, nonunion, stress fracture, bone resorption, deformities, ulnar impingement, carpal degenerative changes in arthroplasty cases, and donor site morbidity (31). Similar to other arthroplasty techniques, reconstruction arthroplasty using non-vascularized fibular graft is associated with high rate of instability and subluxation. In a study by Saikia et al. the most common complication was fibulocarpal subluxation (41.7\%) (18). Also, Chadha et al. treated 9 patients and found that subluxation and graft fracture occurred each in $2(22.2 \%)$ (8). In a similar study, Saini et al. found 3 patients with subluxation (25\%) (32). In all of the studies by Saikia et al., Chadha et al., and Saini et al., postoperative range of motion and functional outcomes were moderately satisfactory and comparable $(8,18,32)$. Conversely, Bassiony reported no case of subluxation. His patients had satisfactory functional outcomes and range of motion. One patient required arthrodesis (10\%) (9).

Although arthroplasty with non-vascularized fibular grafting has yielded acceptable outcomes in certain studies (9), yet because of the high rate of subluxation following arthroplasty $(8,18)$, some surgeons preferred arthrodesis after en bloc resection. Flouzat-Lachaniette et al. treated 13 patients with distal radial GCT with limited arthrodesis after en bloc resection and reconstruction with nonvascularized fibular autograft. The functional score was satisfactory, however, ranges of wrist motion was limited. The most important problem was that 5 patients (38.5\%) required a second operation within 6 years yet no revision surgery (10). With regards to the outcomes of previous reports, the patients were treated with en bloc resection and reconstruction using non-vascularized fibular 
graft followed by partial wrist arthrodesis. In the technique used here, the graft-host fixation at both sides was done using an intramedullary rush pin and a plate was not used because it may have caused soft tissue irritations, hardware prominency or complicate revision surgery. In the current series, the mean union time was 8.4 months and there was no case of nonunion so it seems that using intramedullary fixation is a simple technique that provides acceptable stability, comparable union time to other studies and lower cost, especially in developing countries. Also the results showed no wrist instability in the final follow up yet lower overall range of motion compared to arthroplasty. Although another surgery was required because of tumor recurrence in 2 cases, none of patients underwent revision surgery because of progressive degenerative changes, pain or donor site morbidity during the follow up period. The described technique uses a relatively simple method of raising a non-vascularized fibular shaft graft to obtain good stability and some mobility of the wrist by performing a partial carpal fusion between fibula, scaphoid, and lunate.

The current study demonstrated that replacement of excised distal radius with non-vascularized fibular shaft autograft, following en bloc resection and partial arthrodesis using an intramedullary pin, could serve as an appropriate treatment of distal radial GCT.

Like other studies, the current study had a number of limitations. The current study was descriptive and the results were not compared with other techniques. Also, it seems that more patients and long-term follow up are needed for more reliable outcomes. In the described technique, the pin should not be removed until union of the radio-fibular junction and wrist, which can be bothersome and irritate the extensor tendon. Also, this could explain the cause of more limited ROM in the patients compared to other studies.

In conclusion, the current study demonstrated that en bloc resection and partial wrist arthrodesis using nonvascularized fibular autograft is an appropriate treatment option for patients with distal radial GCT. The current study only used a rush pin for fixation of the graft and arthrodesis, which could be a suitable option in developing countries regarding the cost of treatment. Unfortunately, 2 patients experienced recurrent tumor. Progressive degenerative changes, pain or donor site morbidity were not found in the patients of the current study. The functional outcomes were acceptable and patients were satisfied with the outcomes.

\section{Footnotes}

Authors' Contribution: Study main concept: Davod Jafari, Hooman Shariatzadeh, and Mohammad Ali Okhovatpour; study concept, design, drafting the manuscript, and critical revision of the manuscript: Davod Jafari, Hooman Shariatzadeh, Mohammad Ali Okhovatpour, Mehran Razavipour, Farshad Safdari; analysis and interpretation of data: Mehran Razavipour, Farshad Safdari, and Mohammad Ali Okhovatpour; study supervision: Davod Jafari, Hooman Shariatzadeh, and Mohammad Ali Okhovatpour.

Financial Disclosure: The authors did not receive any funding or grants in support of their research or preparation for this work.

\section{References}

1. Panchwagh Y, Puri A, Agarwal M, Anchan C, Shah M. Giant cell tumor - distal end radius: Do we know the answer?. Indian J Orthop. 2007;41(2):139-45. doi: 10.4103/0019-5413.32046. [PubMed: 21139767].

2. Dahlin DC, Cupps RE, Johnson EJ. Giant-cell tumor: a study of 195 cases. Cancer. 1970;25(5):1061-70. [PubMed: 4910256].

3. Harness NG, Mankin HJ. Giant-cell tumor of the distal forearm. J Hand Surg Am. 2004;29(2):188-93. doi: 10.1016/j.jhsa.2003.11.003. [PubMed: 15043887].

4. Szendroi M. Giant-cell tumour of bone. J Bone Joint Surg Br. 2004;86(1):5-12. [PubMed: 14765857].

5. O’Donnell RJ, Springfield DS, Motwani HK, Ready JE, Gebhardt MC, Mankin HJ. Recurrence of giant-cell tumors of the long bones after curettage and packing with cement. J Bone Joint Surg Am. 1994;76(12):1827-33. [PubMed: 7989388].

6. Liu YP, Li KH, Sun BH. Which treatment is the best for giant cell tumors of the distal radius? A meta-analysis. Clin Orthop Relat Res. 2012;470(10):2886-94. doi: 10.1007/s11999-012-2464-7. [PubMed: 22773395].

7. Vander Griend RA, Funderburk $\mathrm{CH}$. The treatment of giant-cell tumors of the distal part of the radius. J Bone Joint Surg Am. 1993;75(6):899-908. [PubMed: 8314830].

8. Chadha M, Arora SS, Singh AP, Gulati D, Singh AP. Autogenous non-vascularized fibula for treatment of giant cell tumor of distal end radius. Arch Orthop Trauma Surg. 2010;130(12):1467-73. doi 10.1007/s00402-010-1059-6. [PubMed: 20143078].

9. Bassiony AA. Giant cell tumour of the distal radius: wide resection and reconstruction by non-vascularised proximal fibular autograft Ann Acad Med Singapore. 2009;38(10):900-4. [PubMed: 19890583]

10. Flouzat-Lachaniette $\mathrm{CH}$, Babinet A, Kahwaji A, Anract P, Biau DJ. Limited arthrodesis of the wrist for treatment of giant cell tumor of the distal radius. J Hand Surg Am. 2013;38(8):1505-12. doi: 10.1016/j.jhsa.2013.04.026. [PubMed: 23809472].

11. Chung DW, Han CS, Lee JH, Lee SG. Outcomes of wrist arthroplasty using a free vascularized fibular head graft for Enneking stage II giant cell tumors of the distal radius. Microsurgery. 2013;33(2):112-8. doi 10.1002/micr.22028. [PubMed: 22976356].

12. Clarkson PW, Sandford K, Phillips AE, Pazionis TJ, Griffin A, Wunder JS, et al. Functional results following vascularized versus nonvascularized bone grafts for wrist arthrodesis following excision of giant cell tumors. J Hand Surg Am. 2013;38(5):935-940 e1. doi: 10.1016/j.jhsa.2012.12.026. [PubMed: 23455409].

13. McLean JM, Clayer M, Stevenson AW, Samson AJ. A modified ulnar translocation reconstruction technique for Campanacci grade 3 giant cell tumors of the distal radius using a clover 
leaf plate. Tech Hand Up Extrem Surg. 2014;18(3):135-42. doi: 10.1097/BTH.0000000000000053. [PubMed: 24922329].

14. Duan H, Zhang B, Yang HS, Liu YH, Zhang WL, Min L, et al. Functional outcome of en bloc resection and osteoarticular allograft reconstruction with locking compression plate for giant cell tumor of the distal radius. J Orthop Sci. 2013;18(4):599-604. doi: 10.1007/s00776-013-03941. [PubMed: 23661178].

15. Pazionis TJ, Alradwan H, Deheshi BM, Turcotte R, Farrokhyar F, Ghert M. A Systematic Review and Meta-Analysis of En-Bloc vs Intralesional Resection for Giant Cell Tumor of Bone of the Distal Radius. Open Orthop J. 2013;7:103-8. doi: 10.2174/1874325001307010103. [PubMed: 23730371].

16. Puri A, Gulia A, Agarwal MG, Reddy K. Ulnar translocation after excision of a Campanacci grade-3 giant-cell tumour of the distal radius: an effective method of reconstruction. J Bone Joint Surg Br. 2010;92(6):875-9. doi: 10.1302/0301-620X.92B6.23194. [PubMed: 20513888].

17. Zhu Z, Zhang C, Zhao S, Dong Y, Zeng B. Partial wrist arthrodesis versus arthroplasty for distal radius giant cell tumours. Int Orthop. 2013;37(11):2217-23. doi: 10.1007/s00264-013-2040-0. [PubMed: 23925879].

18. Saikia KC, Borgohain M, Bhuyan SK, Goswami S, Bora A, Ahmed F. Resection-reconstruction arthroplasty for giant cell tumor of distal radius. Indian J Orthop. 2010;44(3):327-32. doi: 10.4103/00195413.65134. [PubMed: 20697488].

19. Campanacci M, Guinti A, Olmi R. Giant cell tumor of bone A study of 209 cases with long-term follow up in 130. Italian J Orthop and Traumat. 1975;1:249-77.

20. Enneking WF, Dunham W, Gebhardt MC, Malawar M, Pritchard DJ. A system for the functional evaluation of reconstructive procedures after surgical treatment of tumors of the musculoskeletal system. Clin Orthop Relat Res. 1993(286):241-6. [PubMed: 8425352].

21. Goldenberg RR, Campbell CJ, Bonfiglio M. Giant-cell tumor of bone. An analysis of two hundred and eighteen cases.J Bone Joint Surg Am. 1970;52(4):619-64. [PubMed: 5479455].
22. Smith RJ, Mankin HJ. Allograft replacement of distal radius for giant cell tumor. J Hand Surg Am. 1977;2(4):299-308. [PubMed: 330615].

23. Cheng CY, Shih HN, Hsu KY, Hsu RW. Treatment of giant cell tumor of the distal radius. Clin Orthop Relat Res. 2001(383):221-8. [PubMed: 11210959].

24. Lackman RD, McDonald DJ, Beckenbaugh RD, Sim FH. Fibular reconstruction for giant cell tumor of the distal radius. Clin Orthop Relat Res. 1987(218):232-8. [PubMed: 3568485].

25. Jamshidi K, Modaresnejad H. Osteoarticular allograft reconstruction of the distal radius after giant cell tumor resection. MJIRI. 2008;22(1):1-7.

26. Kocher MS, Gebhardt MC, Mankin HJ. Reconstruction of the distal aspect of the radius with use of an osteoarticular allograft after excision of a skeletal tumor. J Bone Joint Surg Am. 1998;80(3):407-19. [PubMed: 9531209].

27. Pho RW. Malignant giant-cell tumor of the distal end of the radius treated by a free vascularized fibular transplant. J Bone Joint Surg Am. 1981;63(6):877-84. [PubMed: 7240328].

28. Bickert B, Heitmann C, Germann G. Fibulo-scapho-lunate arthrodesis as a motion-preserving procedure after tumour resection of the distal radius. J Hand Surg Br. 2002;27(6):573-6. [PubMed: 12475519].

29. Murray JA, Schlafly B. Giant-cell tumors in the distal end of the radius. Treatment by resection and fibular autograft interpositional arthrodesis. J Bone Joint Surg Am. 1986;68(5):687-94. [PubMed: 3722225].

30. Starr DE. Congenital absence of the radius. A method of surgical correction. J Bone Joint Surg Am. 1945;27(4):572-7.

31. Dhammi IK, Jain AK, Maheshwari AV, Singh MP. Giant cell tumors of lower end of the radius : problems and solutions. Indian J Orthop. 2005;39:201-5.

32. Saini R, Bali K, Bachhal V, Mootha AK, Dhillon MS, Gill SS. En bloc excision and autogenous fibular reconstruction for aggressive giant cell tumor of distal radius: a report of 12 cases and review of literature. J Orthop Surg Res. 2011;6:14. doi: 10.1186/1749-799X-6-14. [PubMed: 21385393]. 